\title{
Revitalization measure in Suzu city based on questionnaire
}

\author{
T. Oyabu \\ Kanazawa Seiryo University, Japan
}

\begin{abstract}
Suzu city is located at the tip of Noto Peninsula in Ishikawa Prefecture of Japan. In the city, the ratio of workers engaged in the primary industry is $20 \%$. The value is higher in the prefecture and ranks fourth. In other words, it is desired to utilize the primary articles. Especially, attractive foods which are based on fishing and farming are necessary as one of the unique resources. It becomes obvious that the ratio of lodgers from other prefectures reaches $70 \%$ as the research result on trend of visitors to the area. The area has a potential to increase the lodger number depending on a measure. There are some agendas. One of them is to take much time to access. It takes two and half hours from Kanazawa city which is the capital city of Ishikawa prefecture and takes forty minutes from Noto Airport by car. This study arrives at the conclusion that it needs a local revitalization which is centered on "roadside stations" (Michi-no-eki in Japanese). There are three roadside stations in Suzu city. The stations are familiar to nearly all citizens and tourists. Revitalizing measures could be constructed by applying the three stations as a triangle. And there are many tourist sites, for example: Enden-village, Mituke-island and Rokkouzaki lighthouse. Fresh food and the experience of the salt garden are attractive to tourists. The questionnaire survey was carried out to write up the needs of inhabitants on Michi-no-eki. The high-ratio need was a diner and coffee shop.

Keywords: roadside station, Primary industry, aging, increasing measure, visitor number.
\end{abstract}

\section{Introduction}

Since the bankruptcy of Lehman Brothers which was one of the major American investment banks, the world financial crisis was causing. The bankruptcy 
occurred on September 15, 2008. Japan received immediately various kinds of influences from other countries in an increasingly globalized world. Japan was imposed additionally a strain due to the Great East Japan Earthquake which occurred on March 11, 2011. Economic stagnation caused temporarily and the Japanese could not worry about one's trip due to social trend. Foreign tourists to Japan decreased sharply and many foreigners in Japan came back temporarily to one's country [1]. The tourist industry in Japan is deeply-impacted even now but there are some signs of revitalization with the recovering of corporate activity [2]. Various kinds of disaster-impacts caused around the world have an affect even on Japan's regional cities. It is necessary for local governments to become independent and to decrease the various kinds of risks [3]. One of the measures for decreasing risks is a promotion by tourism. There are many areas of tourism as a field. Tourisms drawing visitor's attention are a content tourism, for example animation and movie, and food tourism.

In Suzu city of Ishikawa prefecture, population decline and aging population are rapidly increasing and it is difficult to maintain some communities in the city. It is the same tendency with other rural areas in Japan. It is necessary to construct a measure for local revitalization due to increasing visitor numbers and extending the length of the stay. The following items are important to revitalize the rural community, namely people, goods, money and information. Whole items are not necessary. The scarcity-item should be complemented using the sufficient items. The most important thing is personal exchange. In this study, the need of the exchange is indicated using statistical data of Suzu city. There are three roadside stations (Michi-no-eki in Japanese) in the city and it is necessary to make an effective use of the stations to revitalize the city. The station's names are: Suzunari, Suzu-enden-mura and Noroshi. As for the result, the acceleration of the use of the three stations is needed by exchanging the people, goods, money and information. The three stations form a triangle. The stations are deeply associated with the local people and have various kinds of function. There are about 970 stations in Japan. Transportation is a vehicle in Japanese rural area. The use of roadside stations is essential [4].

\section{Outline of Suzu city}

\subsection{Population change}

Suzu city is on the Japan Sea and has been one of Regional Urban Core Areas from ancient times. The city covers an area of approximately $240 \mathrm{~km} 2$. The population variation with time in the city is indicated in Fig. 1. It was 35,160 in 1962 and was 17,327 in 2010 . The value has decreased by 50 percent [5]. The number of households was decreased from 7,341 to 6,535 (about 10 percent lower) and showed a trend in nuclear families. There are ten sections in the city. The average number of people per household was down from 4.17 in 1970 to 2.6 in 2010, and the falling birthrate and the aging population were rapidly accelerating. 


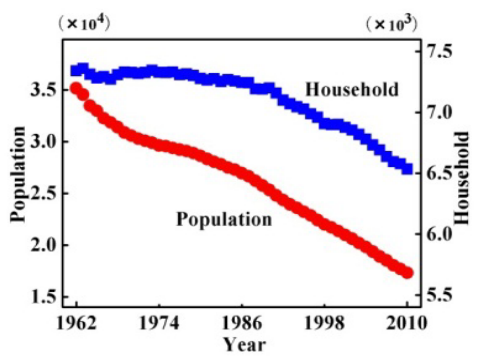

Figure 1: $\quad$ Population change in Suzu city.

\subsection{Population composition by industry}

The ratio of people engaging in agriculture, forestry and fishery is higher in Suzu city. Many of the people have additional jobs. The ratio of workers engaging in each industry was as follows. Primary industry was 20.1, secondary manufacturing was 28.2 and tertiary industry was $51.7 \%$ respectively in 2005 . In Suzu city, the ratio of primary industry is larger compared with other autonomies and it ranks fourth among 41 autonomies. The number of fishermen is decreased markedly and the variation with time is shown in Fig. 2. It is significantly decreasing until 2003 by the rapid aging of society. It is necessary to enforce a measure which makes a living of residents by personal exchanges. One of the measures is the use of Michi-no-eki. Many tourists visit the facility and buy souvenirs which are special primary products and the processed products. Some experiencing classes are held in Michi-no-eki. There is a possibility for the tourists to settle down.

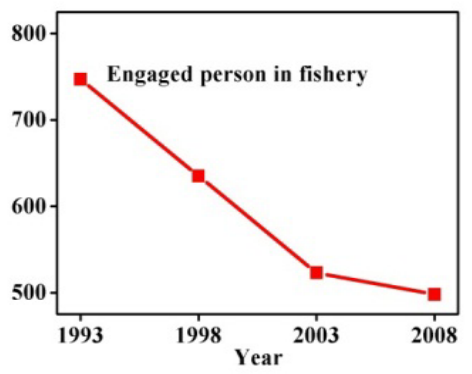

Figure 2: $\quad$ Population change in persons engaged in fishery.

\subsection{Tourism}

Inbounds of tourism in Suzu city is on a declining trend, namely the number of day-trippers and lodgers is decreasing from year to year. In 2007, the city sustains damages from the earthquake in Noto peninsula. Noto airport opened in 2003 and there are two flights to Haneda (Tokyo, about 60 minutes) every day. The airport did not work as a brake against population decrease even though it 
had a high degree of expectation for revitalization in the Noto area. The timedependent change of day-tripper number is illustrated in Fig. 3. In the figure, there is a marked decline from 1993 to 1998 and also in 2003. This characteristic in 2003 results from the earthquake in Noto peninsula. The characteristic of lodger number is shown in Fig. 4. It also has same tendency. Opening of Noto Airport does not have significant impact on inbounds. It is impossible to restrain from decreasing inbounds and some measure is needed to increase visitornumber. The scattering diagram between day-tripper and lodger number is indicated in Fig. 5. There is a positive correlationship in the figure and the direction of the plots is on the track to origin. It is requested for the direction to turn around.

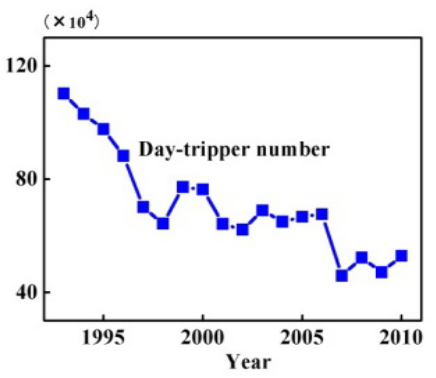

Figure 3: Change of day-tripper number in Suzu city.

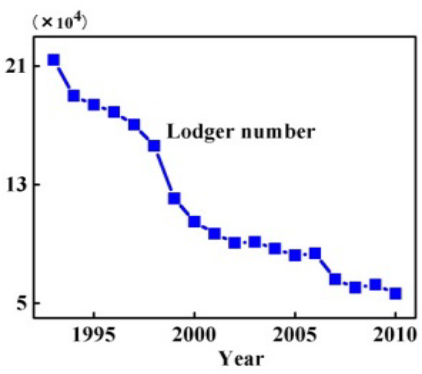

Figure 4: Change of lodger number.

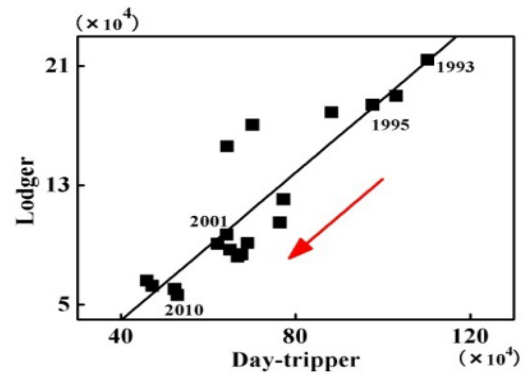

Figure 5: Correlationship between day-tripper and lodger number. 
The lodging capacity in Suzu city is not very large; the number of Japanese inns and hotels is nine, minshuku (half board) is twenty seven and public facility (a kind of hotel) is one in 2011. The role of minshuku is important. Visitors from other prefectures make up 70\%. Departure places of lodger persons from other prefectures in 2010 are shown in Fig. 6. The visitors from Toyama prefecture which is a surround is a big part. The ones from Kansai (Osaka), Chukyo (Nagoya) and Kanto (Tokyo) account for about 20\% respectively. These are three major metropolitan areas in Japan. That means big advantage. Effective PR measure could be easily constructed. Annual fluctuation in visitor numbers is also important with the capacity of facility. The variation of day-tripper numbers in 2010 is exhibited in Fig. 7. The monthly average is 44,100 persons and the values in May and August have a peak. It reaches 133,881 persons in August (n8). The one for January (n1) is 17,198 and is the smallest. Day-tripper number is small in winter. The $\mathrm{n} 1$ is only $13 \%$ of $\mathrm{n} 8$. It is required to increase visitors due to various kinds of events in winter. The fluctuation of lodger number also denotes the same tendency of the day-tripper. The annual fluctuation of lodger number in 2010 is shown in Fig. 8. The number in February is the smallest and the value is 1,928. The one in August is the largest and is 14,446 which takes 7.5 times the one in February. There is a strong correlationship between daytripper and lodger characteristics. There are magnetic resources seasonally in the city. The person from the surrounding prefecture and city takes a one day trip to the area. A distant visitor takes up lodging. If distant visitors and neighbors could stay at a hotel according to a planned event, the event is fairly effective. Participatory and experience-based events are a key.

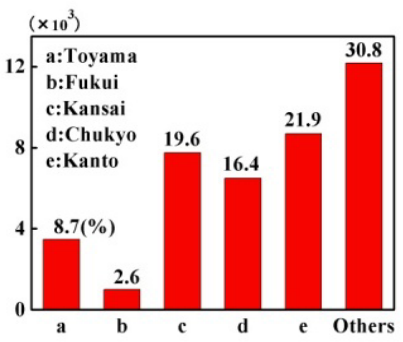

Figure 6: $\quad$ Ratio of departure place on lodger from other prefecture.

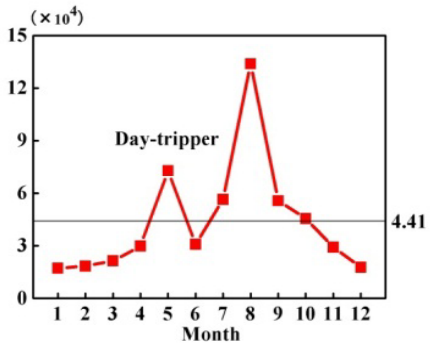

Figure 7: Annual fluctuation of day-tripper. 


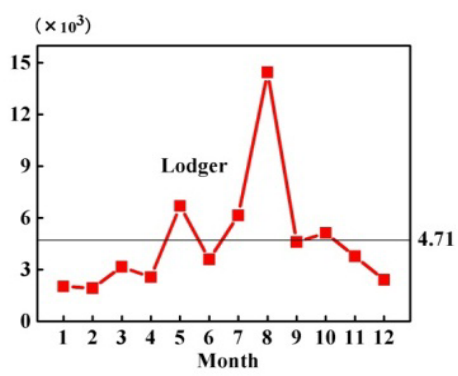

Figure 8: Annual fluctuation of lodger number.

\subsection{Michi-no-eki}

There is not a railway terminal in Suzu city, so road trip is basic. Most Japanese households own a car with the progress of motorization. It takes 2 hours from North Interchange of Hokuriku Expressway to Suzu city by car (total length is about $110 \mathrm{~km}$ ). The length from Kanazawa city is about $150 \mathrm{~km}$ and it takes 2 hours and half using Noto toll road. It takes 40 minutes from Noto Airport. Most inhabitants in the city also have a car. Therefore, the utilization of "Michino-eki" (roadside station) is very attractive, which is certified by Ministry of Land, Infrastructure, Transport and Tourism of Japan. There are 970 stations in the nation in 2011 and there are three stations in the city, namely Noroshi (opened in Apr. 2010), Suzunari (opened in Apr. 2010) and Suzu-enden-mura (opened in Apr. 2006). Whole stations are generally-supported by the local public and the use is expected. Suzunari has a complete range of functions out of the stations, that is, fully-stocked, tourism information and space. The facility plays a central role to the local public and tourist. However, it is necessary to hold some events from the aspect of local area. The city can provide various kinds of good fresh ingredients because the weight of primary industry is higher from time immemorial in the area. Food tourism utilizing the ingredients, nature landscape, local history and culture and infrastructure on ICT are advantage [6]. It is hoped to construct the system that the inhabitants and visitors can gather the necessary information from Michi-no-eki.

The weakness of Suzu city is the access time and the strong points beyond the weakness is required. The important strong point is the delightful outlook. Tateyama mountain range can be seen in the area [7]. Use of ICT which is based on white space of radio wave can be also possible. The effect will be highest when various kinds of strong points work together as focusing on Michi-no-eki and working closely with municipal government. It is imperative that the linkage between the bureaucracy and the private sector is implemented. There is a following matter as a strong point, that is, Shinkansen will open in March in 2015. Access time from Kanto region (including Tokyo) will fairly decrease. There are two as Shinkansen stations, namely Kanazawa and Takaoka. Transportation from the station (secondary transportation) could be taken into account. It is necessary to find a way to collaborate with Takaoka and Himi 
cities, and free or discount bus-service is effective. Access which is a weak point in Suzu will be palliated. Proposed bus route is as follows;

Kanto area - (Shinkansen) - Takaoka - (bus) - Himi - (bus) - Suzu city. There are some threats and the word is used in SWOT analysis. Most-watched threats are strength of brand in Wakura spa and Wajima. In Wajima city, the famous morning market is held. It is necessary to adopt a strategy against the brands. In Noto Peninsula including Wakura, Wajima and Suzu, there is not much difference in foods, history and culture. The salt farm is a unique resource in the Suzu area. The traditional method of salt production has been handed down over the generations so that some persons produce the handmade salt using sea water even today. The history and salt-farming experience could lead to an increase in visitors. Restaurants and coffee houses are very few in the neighborhood of the three stations.

\section{Sales amount of Suzunari}

There are three Michi-no-ekis in Suzu city. One of them is "Suzunari" which plays the leading role and has a function of a bus center. There are many households near the facility and city office is also located surrounding area. And there is a big shopping mall near the one. It is necessary to provide unique goods rather than competitive purchased goods. Suzunari opened in April 2010. Monthly number of customers is shown in Fig. 9. There are two peaks in the figure, namely in May and August. It is thought that there are a lot of visitors in the months. The average number of customers is predicted as follows. Potential guest number $\left(c_{n p}\right)$ is derived as an average value of guest number in June and the ones from October to March. The potential number means the number of local citizen who buy the purchased goods routinely. The value is derived as $c_{n p}$ $=2,357$. The total guests are derived by adding the number of tourists to $c_{n p}$. The change of sales is represented similarly in Fig. 10. The potential amount of sales $\left(s_{v p)}\right.$ is introduced as with Fig. 9 and the value is $s_{v p}=3.022(* 106)$ yen (percapita 1,200 yen). Average customer-spend for tourist is regarded as 1,352 yen in May 2011. The one in August 2011 is 2,370 yen. Purchasing power of tourist in August is much higher.

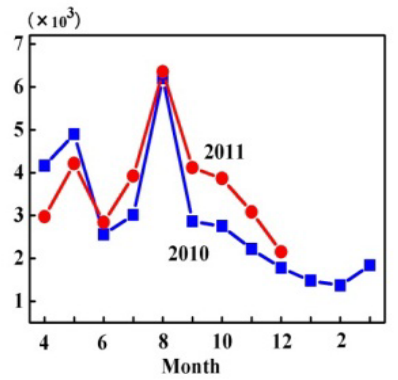

Figure 9: Monthly guest numbers in Suzunari. 


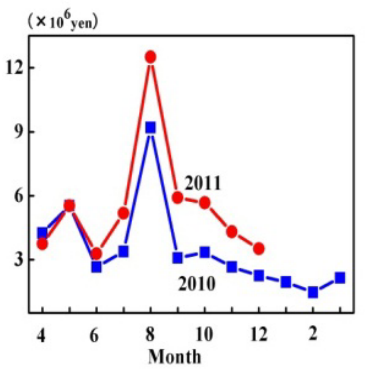

Figure 10: Fluctuation in sales.

Scattering diagram for customer number and sales is exhibited in Fig. 11. The plot for August locates in a unique position. High correlation is recognized and the coefficient is 0.93 . More customers get into more sales. It is necessary that the tourists in August have specific charm to the selection of goods seasonally.

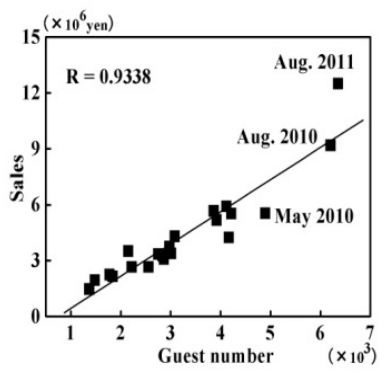

Figure 11: $\quad$ Scattering diagram for guest number and sales.

\section{Results of the questionnaire survey}

A questionnaire survey was carried out to the residents living in the vicinity of three Michi-no-ekis. Questionnaires are handed out to neighboring households individually and the answers are sent by postal mail. Three questionnaire sheets are handed out to each household. The number of sent households is 160 and the number of answer sheets is 112 from 63 households. Most were from aged household and only one sheet per household. The collection rate to distributed households is $39 \%$ and there are a lot of collecting sheets from Suzunari area which is thickly inhabited. The monthly average use is three and it is necessary to get a lot more use. The most of grading in satisfaction level is "normal" and it has a normal distribution. The largest age group was 60 or over and made up $50 \%$. The $40 \mathrm{~s}$ and $50 \mathrm{~s}$ are $15 \%$ respectively. Other generations are about $10 \%$. The company worker and family-operated business as occupation of respondents make up about $48 \%$ and full-time housewives account for 19\%. As for the purpose of use, about $29 \%$ of the local public is to purchase a souvenir and secondary fresh vegetable. Each station sells a special and nice soft serve ice 
cream (for example cream including a very small amount of salt). The one is popular with the habitants living near the stations. Safety and security of foods attracts rising attention in the areas. Consumer groups their purchases with big supermarket located near Suzunari.

The following events are taken as use of Michi-no-eki due to the questionnaire results, which are listed in Fig. 12. Many relate to eating and the habitants demand cheapest foods which use the local ingredients. Suzunari has largest number of guests out of three roadside stations. When taking account of more local utilization, it is necessary for the stations to work together with a central focus on Suzunari. Disaster countermeasure is especially required since the Great East Japan Earthquake. A system for cooperation among three stations must be constructed, for example in the storage of supplies and the flexibility. Fortunately, two stations are located in the north part of Noto Peninsula (external side) and another is located in internal side in which Suzunari is located. This distribution is favorable for countermeasure against tsunami. The facilities must transmit the attractive information on tourism and municipal government. The conceptual diagram is represented in Fig. 13.

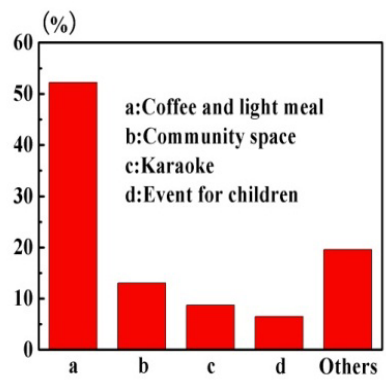

Figure 12: Additional utilization of Michi-no-eki due to habitants.

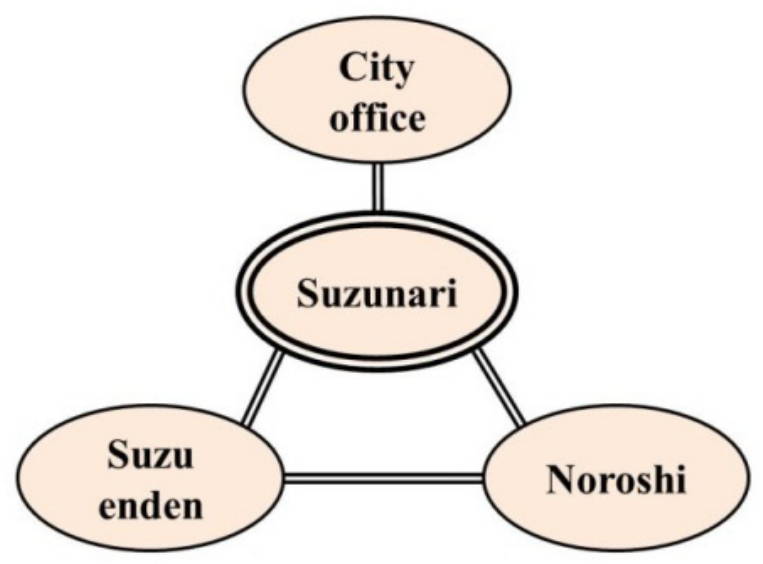

Figure 13: Diagram for cooperation. 
[coffee shop and diner, B-grade gourmet competition (popular and commonly-eaten dishes), karaoke, flea market, large morning bazaar, community space (including lounge), event for children, experiencing class, small library].

\section{Conclusion}

In this study, revitalization measure in Suzu city is organized using statistical data and questionnaire results. There are three Michi-no-ekis in the city, which is located at the tip of Noto Peninsula. The area is a key site in the time of northwest pacific region. The number of visitor will increase when Shinkansen open to Kanazawa in March of 2015. Therefore, it is necessary to take a measure by inhabitants and local government which join together, and is also necessary that they reaffirm the attractive regional resources. The measure will be transitional one when it is not supported by inhabitants. Therefore, promotion of primary product is indispensable, which is important in the city. The incentive plan will be constructed using the system of local production for local consumption instead of cheap ingredients from other areas. At that time, Michino-eki will play an important role with a core of the system. The station should provide various kinds of information and circulars to inhabitants and visitors with hospitality strategy. The information is based on "buy, eat, stay, see and experience" which are absolutely imperative for tourist. It is thought that this leads the area to limit population decrease and aging society.

Shops for light refreshment, karaoke and community space are needed desired as the use of Michi-no-eki by the peripheral people due to the questionnaire result. Information transmission to tourists and inhabitants utilizing ICT is also necessary. The information should be for daily living and useful.

\section{References}

[1] Hokuriku Cyunichi Shinbun (Newspaper): "Decrease visitors to Japan by 50\%", third page (Jun.17, 2011).

[2] Yomiuri-shinbun (Newspaper): "A recovery sign of foreign visitors to Japan", nine page (Jul.17, 2011).

[3] Dirk Glaesser: "Crisis Management in the Tourism Industry", Kumpul (April 2008).

[4] Mitsuhiro Seki and Hiroshi Sakamoto: "Michi-no-eki / Hub of intercommunication and local promotion center", Shin-hyoron (July 2011).

[5] The city office of Suzu: "Statistical data in Suzu", (May 2011).

[6] Report of Ministry of Internal Affairs and Communications: "Advantage region Oku-noto using ICT",(July2011).

[7] Soshiro Ohsumi: "Hands-on experts: Strategic management for autonomy", Dai-ichi-hoki (August 2005). 